\title{
FIGO Grade 3 Endometrial Endometrioid Adenocarcinoma
}

National Cancer Institute

\section{Source}

National Cancer Institute. FIGO Grade 3 Endometrial Endometrioid Adenocarcinoma. NCI

Thesaurus. Code C40148.

A primary endometrioid adenocarcinoma of the endometrium that contains more than

$50 \%$ non-squamous solid areas. 